\section{Infantile hypertrophic pyloric stenosis}

Sir,

The nice summary article of 'Infantile hypertrophic pyloric stenosis in Belfast, 1957-1969' by J. A Dodge (Archives, 1975, 50, 171) refers in part to jaundice noted in $1.8 \%$ of such patients before operation. In hypothesizing on the subject he fails to mention my favourite thesis, which is that such jaundiced infants have a fairly marked alkalosis and it is this alkalosis which inhibits the activity of the glucuronyl transferase. On occasion there have been infants seen who, on rehydration, clinically seem to clear their jaundice. Unfortunately the definitive study of doing a bilirubin before hydration and correction of alkalosis and then after (but before operation) has not been done. Perhaps Dr. Dodge might comment.

WILLIAM D. COCHRAN
Harvard Medical School,
Joint Program in Neonatology,
221 Longwood Ave.,
Boston, Mass. 02115, U.S.A.

Dr. Dodge comments as follows:

I was interested to read Dr. Cochran's kind comments on my article, and in particular his views on the occurrence of jaundice in infantile pyloric stenosis, and apologize for overlooking the possibility that alkalosis may be a contributory factor.

There is no doubt that correction of metabolic ababnormalities is an important factor in the resolution of jaundice in these babies, but there is no good evidence that it is the restoration of fluid or of acid-base balance which effects the response. Thus, in the only one of my 12 jaundiced patients with really adequate biochemical documentation, there was no clinical evidence of dehydration and his plasma bicarbonate was $24 \mathrm{mEq} / 1$ on admission and rose to $30.6 \mathrm{mEq} / 1$ on the day of operation ( 3 days later), by which time the jaundice was already fading. I remember attending a C.P.C. in Boston on 29 November 1961, when Dr. Cochran himself discussed a jaundiced 'pyloric'. The patient's bicarbonate level was recorded as $24.8 \mathrm{mEq} / \mathrm{l}$.

It seems to me that the most likely explanation for jaundice is impairment of hepatic glucuronyl transferase activity by reduced caloric intake. This hypothesis has been studied by Felsher et al. (1973), who found depressed activity of the UDPG-transferase system in surgical liver biopsies from jaundiced infants with gastrointestinal obstruction, but a tenfold higher level in nonicteric infants with similar disorders. As I pointed out in my article, the association of jaundice with pyloric stenosis in about $2-3 \%$ of affected infants is of the order expected if the true incidence of Gilbert's disease in the population is as high as the $4 \%$ described by $D$. Owens (personal communication, 1974) and Kornberg (1942). Improvement after rehydration is therefore attributable to the glucose or other caloric sources in the intravenous fluids.

J. A. DODGE

Department of Child Health, The Welsh National School of Medicine, Heath Park, Cardiff CF4 $4 X W$.

REFERENCES

Felsher, B. F., Asch, M., Carpio, N., and Wooley, M. (1973). Unconjugated hyperbilirubinaemia in neonates with congenital gastrointestinal obstruction. (Asbt.) Gastroenterology, 64, 151.

Kornberg, A. (1942). Latent liver disease in persons recovered from catarrhal jaundice and in otherwise normal medical students as revealed by the bilirubin excretion test. Fournal of Clinical Investigation, 21, 299.

\section{Maternal protein depletion in small-for-gestational-age babies}

Sir,

We are interested in the findings of $\mathrm{H}$. Stein (Archives, 1975) as we have a series of unpublished data on work done a few years ago at King Edward VIII Hospital, Durban, South Africa. We were at that time mainly interested in hypoglycaemia in the neonate. In a previous pilot study we found that though the tendency to hypoglycaemia was frequent in the low-birthweight (birthweight $<2.5 \mathrm{~kg}$ ) and the small-for-gestational-age infants, the total prevalence of hypoglycaemia was unaccountably high. We are dealing with a population group whose nutritional status is precarious (Powell, 1958; Stein, 1975). It was thus possible that poor maternal nutrition determined the prevalence of hypoglycaemia and at the same time that of small-for-gestational-age babies.

We studied the possible correlation between maternal serum proteins, neonatal blood glucose levels, and the small-for-gestational-age babies. Group A consisted of 99 newborn babies and their mothers: 27 preterm infants, 27 babies of low birthweight, and 53 small-forgestational-age babies. There was an overlap between categories, some babies being placed in more than one category. Group B consisted of 131 normal term babies and 30 of their mothers acting as controls. Means, standard deviations, and standard errors of the means were calculated for all variables in the babies and their mothers, and a comparison of means was made between the group studied and the controls. 